\title{
Prejudice, Ethnic Identity, Contact and Ethnic Group Preferences Among Dutch Young Adolescents
}

\author{
C. N. MASSON ${ }^{1}$ AND M. VERKUYTEN \\ Erasmus University Rotterdam
}

\begin{abstract}
Social identity theory, the contact hypothesis, and prejudice research are three important perspectives for studying ingroup formation and preferences in the context of ethnic groups. This paper studies the utility of the three perspectives in a particular interethnic group context among 160 Dutch subjects between 12 and 15 years of age. The results show that the evaluation of ethnic identity and rate of cross-ethnic contact are strongly correlated with ingroup formation and preference. Prejudicial attitudes seem to be dependent on contact and especially on the evaluation of ethnic identity. Prejudice seems to be a function of positive identification with the Dutch as a group. Applied implications for ethnic-group relations are discussed.
\end{abstract}

This study is concerned with the importance of the evaluation of ethnic identity, prejudicial attitudes toward ethnic minorities, and amount of crossethnic contact for ethnic group preferences among Dutch young adolescents in the Netherlands. Although many empirical studies have looked into these four aspects, most of them are concerned with children (see Aboud, 1988) and have not studied the relationship between the four simultaneously. Studies among adolescents are relatively rare. Bagley, Verma, Mallick, and Young's study (1979) is one of the few examples of studies on prejudice and self-evaluation among British and Dutch adolescents. The studies by Ullah (1987) and Hutnik (1986) are two examples of studies on the relationship between ethnic identity and group relations among British minority groups. The first study reports such a relationship, but the second one does not. Verkuyten (1991) studied this relationship among Dutch minority groups and found a positive association. Rotheram-Borus's study (1990) is an example from the U.S. of a study among ethnic minority and majority adolescents. Across ethnic groups, subjects reporting a strong ethnic identification held more separatist attitudes, engaged in less cross-ethnic contact, and reported more cross-ethnic conflict (see also the review by Phinney, 1990).

A study of the importance of ethnic identity, prejudice, and cross-ethnic contact for group preferences has considerable practical relevance, especially in the field of education and for programs intending to stimulate interethnic

\footnotetext{
${ }^{1}$ Correspondence concerning this article should be addressed to Dr. C. N. Masson, Social Psychology Section, Department of Law, Erasmus University Rotterdam, P.O. Box 1738, NL-3000 DR Rotterdam, The Netherlands.
}

\section{6}

Journal of Applied Social Psychology, 1993, 23, 2, pp. 156-168.

Copyright $\odot 1993$ by V. H. Winston \& Son, Inc. All rights reserved. 
relations. Group relations continue to fascinate social scientists and for some it is the major topic in their field. Social psychologists, in particular, try, among other things, to analyze the psychological processes in intergroup relations. For explaining intergroup relations in the context of ethnic groups, there are three important perspectives: the social identity model, the contact hypothesis, and prejudice research. These perspectives do not have the same theoretical "status." For instance, social identity theory offers a specific framework for understanding group relations and allows for the formulation of falsifiable hypotheses, whereas research on prejudice is a vast domain. However, all three perspectives point to variables that are considered important for understanding ethnic group relations. Moreover, all three often are discussed simultaneously and sometimes are considered also in the same general model (Hewstone \& Brown, 1986). Empirically the different variables are studied rarely in relation to each other in order to determine the relative importance of each. Before discussing our study we will elaborate on the three perspectives.

Ethnic group formation and preferences are traditionally studied in relation to prejudice. Theoretically prejudice is conceptualized as an attitude: the negative evaluation of specific ethnic or racial groups or ethnic groups in general. Research typically studies the rejection or dislike of other groups and in doing so implicitly assumes that such a dislike implies a preference for the own group. Most prejudice research does not allow the expression of preference for one's own group and the (dis)liking for the other, simultaneously (see Aboud, 1988). The level of ingroup preference and formation is hardly ever considered, so that it is unclear whether it is inextricably linked with outgroup dislike. There is empirical evidence which questions this association (see Milner, 1984; Verkuyten, 1992), and Hinkle and Schopler (1986) suggest that there are probably different psychological processes that determine the ingroup and outgroup sides of group differentiation. The present study focuses on the level of ingroup preference in trying to extend the understanding of the association between prejudice and group relations.

Social identity theory (Tajfel \& Turner, 1979) stresses that a sense of identity is closely linked with the various group memberships and that this sense has implications for intergroup behavior. First, the way people define themselves seems to be an important condition for psychological group formation (see Turner, 1982). The recognition and acceptance of selfdefining social categories is considered a sufficient condition for ingroup formation and preference, even in the absence of attraction between members or when members dislike each other (Hogg \& Turner, 1985). This relationship is confirmed in several experimental studies (see Hogg, 1987). Second, social identity processes can have implications for intergroup relations if it is assumed that people prefer to have a positive, rather than a 
negative, self-concept. Given that part of our self-concept is defined in terms of group affiliations, it follows that there will be a tendency to view those ingroups favorably in comparison with others. High-status group members are especially likely to show signs of ingroup formation and preference. Sachdev and Bourhis (1987) have shown that high-status group members were more positive about their group membership than were low-status group members, who engaged in significant amounts of outgroup favoritism. In the present study among Dutch young adolescents who belong to the majority group, it was expected that the evaluation of their ethnic identity has relevance for ethnic group preferences. More specifically, it can be hypothesized that a positive orientation toward the ethnic group with which one identifies is associated with greater ingroup preference than a neutral or negative orientation.

Allport (1954) concluded in his classic statement about the contact hypothesis that the outcome of contact would be favorable when participants were of equal status, were pursuing common goals, and were backed by social and institutional support (see also Amir, 1969). Contact between members of different (ethnic) groups can lessen intergroup discrimination and hostility. This has been widely studied. Contact would allow for the discovery of similarities of beliefs and values that are generally found to lead to attraction. However, people can also discover basic dissimilarities through contact, and, moreover, negatively experienced contact can reinforce prejudice and hostility. The contact hypothesis has been criticized on the grounds that the distinction between interpersonal and intergroup contact has been neglected. The first case is concerned with actions of individuals qua individuals, whereas in the second interactions between two or more people are determined by their membership of various social groups or categories. This distinction is especially important because contact research studies the antecedents of interpersonal attraction while being concerned with relationships between groups (Brown \& Turner, 1981). Hewstone and Brown (1986) argue that research has blurred this distinction and has implicitly assumed that interpersonal contact leads to more positive intergroup relations. According to these authors interpersonal contact will not affect intergroup behavior, but intergroup contact will. ${ }^{2}$ Following this line of argument the present study focuses more on intergroup contact and preferences for different ethnic groups rather than on the individual level.

Cross-ethnic contact is mostly studied in terms of its effect on prejudice. In this kind of research not only contact frequency is studied but also type of

\footnotetext{
${ }^{2}$ Brewer and Miller (1984), however, maintain a contrary view and argue that interpersonal relationships across ethnic lines will lead to more favorable outcomes than category-based social interactions.
} 
contact and the evaluation and outcome of the contact. The present study is concerned with the amount of self-reported contact with ethnic minority groups. Studies in Germany with similar minority groups as in the present study (e.g., Turkish people), found more positive attitudes toward minorities with increased contact frequency (see Wagner \& Machleit, 1986). The contact hypothesis states that contact will lead to reduction of prejudice. However, most of the existing studies do not allow determination of the causal direction of the relationship between contact and prejudice. Prejudice can also lead to an avoidance of contact and more ingroup formation and preference. Prejudicial attitude may be not only a result of intergroup relations and contact, but may be an independent determinant of ingroup formation and preference. It could also be argued that prejudicial at titudes determine self-identification and, as a consequence, ingroup formation and preference. However, the social identity model would predict that prejudicial attitudes such as outgroup dislike are the result of social identity processes. Prejudice can be considered a function of identification with a dominant social group or of the need for a positive self-concept. This line of reasoning assumes that ingroup-oriented patterns of preference are accompanied by rejection of other groups, in order to maximize intergroup differentiation.

The present study explores these relationships among Dutch adolescents in order to study the utility of the three perspectives discussed in making sense of a particular interethnic group context. The study concentrates on adolescents who live in a social environment-school and neighborhood-with a high percentage of ethnic minority youth of mainly Turkish, Moroccan, and Surinamese origin. The percentage of ethnic minorities in the schools studied is $50 \%$ or more. There were two reasons to restrict the study to multiethnic schools. First, in these schools there is ample opportunity for interethnic contact. If Dutch youngsters in such a context do not like to interact with ethnic minorities there must be specific and compelling reasons, such as prejudice and self-identification. Second, for Dutch adolescents ethnic identity probably will be a more salient component of their self-concept in situations where the Dutch are not a clear majority (see McGuire, McGuire, Child, \& Fujioka, 1978).

\section{Method}

\section{Sample}

The study was carried out in four secondary schools in Rotterdam. The questionnaires were administered in the classroom under supervision. All subjects participated on a voluntary basis. The population consisted of 160 Dutch respondents between 12 and 15 years of age. Forty-seven percent were 
girls. There were hardly any differences in socioeconomic background because all respondents belonged to the lower strata. Despite the similar socioeconomic background, both Dutch subjects and ethnic-minority subjects considered the Dutch a higher status group (see Verkuyten, 1992).

\section{Instruments}

A Dutch scale developed by De Jong and Van Der Toorn (1984) was used to measure prejudicial attitudes toward ethnic minorities in general. The scale consists of 16 evaluative statements (positive and negative, with five categories) about foreigners and different peoples (e.g., "I never trust people from another country"; "Many foreigners abuse unemployment benefit"; "I prefer to live among people like myself"). Principal components analysis with varimax rotation yielded one main factor with an eigenvalue of 5.6 and $35 \%$ of the variance explained (the second factor had an eigenvalue of 1.3 and accounted for $8 \%$ of the variance). All 16 items had a minimal loading of .31 on the main factor and Cronbach's alpha was .86. The prejudice scale toward minorities in general showed a strong correlation $(.60, p<.001)$ with five evaluative statements concerning Turkish people in comparison with the Dutch (e.g., "Turkish people are less honest than Dutch people"; "Turkish people work harder than Dutch people"). The correlation shows that the general prejudicial attitude toward foreigners also holds toward specific ethnic groups. In the present study the prejudice scale did not correlate significantly with a short version of the Crown-Marlowe social desirability scale $(r=.06, p>.10)$ which was validated for the Netherlands by Nederhof (1981).

For measuring the evaluation of ethnic identity three Likert-type questions (e.g., "Are you proud that you are Dutch") were used (compare Verkuyten, 1990). Principal components analysis showed one factor with $65 \%$ of the variance explained. Cronbach's alpha was .72 .

Two questions were asked about the rate of weekly contact (five categories ranging from every day to never) with contemporaries from ethnic minorities outside and inside school. The two questions correlated $.41(p<.001)$ and have been summated. A higher score means a lower rate of weekly contact.

There were four questions considering the relationships with and preferences for different ethnic groups. Subjects had to make a choice between five different groups rather than individuals within those groups. In other words, the measure of attraction was social rather than individual. The first question considered the self-reported actual relations ("best friends"), and the other questions dealt with preferences (e.g., "Which boys or girls would you prefer to sit next to in the classroom?"; "Which boys or girls would you like to invite home?"). The subjects choose up to three ethnic groups for each 
question posed. A 3-point scale for level of ingroup formation and preference was constructed with the following response categories: only an ethnic minority group; the Dutch and one or two ethnic minority groups; only the Dutch. On the four questions between $50 \%$ and $55 \%$ of the Dutch subjects preferred only Dutch contemporaries. The four questions correlated significantly with each other (lowest correlation was .58, $p<.001$ ). Principal component analysis yielded one factor with $71 \%$ of the variance explained. Hence a composite dependent measure was calculated and a higher score means a higher level of ingroup formation and preference.

\section{Results}

The mean score on the prejudice scale was 47.6 , which indicates a neutral attitude toward ethnic minorities, and the standard deviation was 11 . The majority of the respondents $(67 \%)$ had a neutral or positive attitude toward ethnic minorities and $26 \%$ had a slight negative attitude. There was no significant relationship between age and level of prejudice $(r=.06, p>.10)$. There was, however, a significant difference between boys and girls $(t=2.59$, $p<.01)$. Girls were less prejudiced toward minorities, which is also found in other studies in the Netherlands (e.g., De Jong \& Van Der Toorn, 1984).

The majority of the Dutch subjects $(75 \%)$ reported cross-ethnic contact every day in school. More striking is that in these multiethnic schools $16 \%$ indicated that they hardly ever or never had contact with ethnic minorities. Outside school $47 \%$ of the Dutch subjects reported cross-ethnic contact every day or almost every day and $45 \%$ answered with "hardly" or "never." Boys reported significantly less cross-ethnic contact than girls $(t=2.47, p<$ .05 ). There was no significant effect for age.

Many Dutch respondents preferred only Dutch contemporaries on the four questions posed concerning ingroup preference (between $50 \%$ and $55 \%$ ). There were no subjects who only favored an ethnic minority group. There was no significant difference for $\operatorname{sex}(t=0.27, p>.10)$ or for age.

Table 1 presents the correlations between prejudice, the evaluation of ethnic identity, ethnic group preferences, and cross-ethnic contact. The five measures correlate significantly with each other. The highest correlations are between the evaluation of ethnic identity and prejudicial attitudes toward ethnic minorities and ethnic group preference, respectively. Dutch adolescents who evaluated their ethnic identity more positively showed a more negative attitude toward ethnic minorities and also a higher level of ingroup formation and preference. These subjects also indicated that they had less frequent contact with ethnic minorities. The other correlations show that prejudice was associated with amount of cross-ethnic contact and ethnic group preferences. Although all the intercorrelations were lower among girls 
Table 1

Intercorrelations Between the Different Measures and Stepwise Regression Values ( $\beta$ ) With Ingroup Formation and Preference as the Dependent Variable

\begin{tabular}{lcccc}
\hline & 1 & 2 & 3 & $\beta$ \\
\hline 1. Prejudice & - & & & .14 \\
2. Ethnic identity & $.57^{*}$ & & & $.40^{*}$ \\
3. Rate of contact & $.36^{*}$ & $.31^{*}$ & & $.33^{*}$ \\
4. Ingroup preference & $.43^{*}$ & $.50^{*}$ & $.45^{*}$ & \\
$r^{2}$ & & & & .36 \\
\hline
\end{tabular}

${ }^{*} p<.001$.

than among boys, the pattern of results was similar for both groups. The only exception was that among girls rate of contact was not significantly $(p>.10)$ associated with prejudice $(r=.22)$ or with ethnic identity $(r=.12)$.

The intercorrelations indicate that the measures share a considerable amount of variance. To estimate the relative importance of the three independent variables - prejudice, amount of contact, and the evaluation of ethnic identity-stepwise standardized multiple regression analyses were conducted with ethnic group preferences as the dependent variable. Both the method of stepwise selection (free entry) and forced entry was used. In case of stepwise selection the evaluation of ethnic identity enters the equation first and explained a considerable amount of the variance in ethnic group preferences (see Table 1). Rate of contact also had a significant beta value but explained less of the variance. The beta value for prejudice did not significantly differ from zero $(p>.10)$. Regression analyses among boys and girls separately showed very similar results. For both groups the evaluation of ethnic identity and rate of contact had a significant beta value (for boys respectively .43 and .32 and for girls .40 and .37 ), whereas the value for prejudicial attitude was not significant (for boys .18 and for girls .14).

These results indicate that there is no effect for prejudice apart from the effects for ethnic identity and rate of contact on ethnic group preference. Considering the shared variance of the three independent measures, the forced entry technique was also used. Prejudice was entered first and had a significant beta value $(p<.001)$. In subsequent steps rate of contact and the evaluation of ethnic identity also explained a significant part of the variance (respectively, second step, $p<.001$, and third step, $p<.001$ ). In other words, it was not necessary to include prejudicial attitudes in the equation to 
account for the percentage of variance explained, whereas it was necessary to include rate of contact and ethnic identity. The evaluation of ethnic identity and rate of contact are important variables in explaining ethnic group preferences, and the effect for prejudice seems to be dependent on these two measures.

\section{Discussion}

This study is concerned with the importance of ethnic identity, amount of contact with ethnic minorities, and prejudicial attitudes toward ethnic minorities for ethnic group preferences among Dutch adolescents in multiethnic schools. We explored these relationships and tried to explain the level of ingroup formation and preference among the Dutch adolescents, who are considered a higher-status group in comparison with ethnic minorities. As theoretical perspectives, the social identity model, the contact hypothesis, and the concept of prejudice have been used.

First, it must be stressed that the data presented are correlational and consequently cannot address the question of causality. Theoretical assumptions were the point of departure. For instance, the social identity model predicts that the acceptance and evaluation of a self-defining category causes ingroup formation and preference. In line with this model the present study assumes that the evaluative orientation toward the own ethnic group is an important determinant of the preferences for and associations with the ingroup. Comparable assumptions can be made concerning the contact hypothesis and prejudicial attitudes. It has to be kept in mind, however, that it is certainly plausible that the association with one's own group increases the acceptance and evaluation of own-group membership or the prejudicial nature of the attitude toward ethnic minorities, rather than the other way around. It also must be stressed that in the present study the measures were more social than individual. We were not concerned with interpersonal preferences and relationships but with social identity and intergroup attitudes. As a result this study does not allow us to draw conclusions about how to alter individual relationships where social interactions are determined by individual characteristics.

The analyses showed that the evaluation of ethnic identity correlated strongly with ingroup formation and preference. The more positively Dutch adolescents, boys and girls, evaluated their ethnic identity the greater the level of ingroup formation and preference. This result is in agreement with the social identity model. Social identity processes seem to be important for the level of ingroup formation and preference among Dutch adolescents. In a study among ethnic minority adolescents we found a similar relationship between the evaluation of ethnic identity and ingroup preference (Verkuy- 
ten, 1991). These results pose the practical question of how interethnic relations as well as a positive ethnic identity can be stimulated simultaneously. In order to answer this question not only the ingroup side of ethnic relations has to be studied, but also the outgroup side. It is often assumed that own-group-oriented patterns of preference are accompanied by rejection of other groups. The results suggest that this is true among Dutch adolescents. However, among adolescents from ethnic minorities living in the Netherlands there seems to be no such tendency (Verkuyten, in press). This indicates that important obstacles for improving interethnic relations are to be found among the higher status group.

Amount of contact with ethnic minorities had also a significant effect on ingroup formation and preference. More frequent cross-ethnic contact was associated with less ingroup formation and preference. This suggests that stimulating contact can diminish own-group oriented patterns of preferences and relations. Such a strategy seems appropriate even in multiethnic schools. The results show that in schools with a very high percentage of pupils from ethnic minorities, ingroup preferences among Dutch adolescents were fairly strong. Although the majority of the subjects had frequent contact with ethnic minority contemporaries, even in these schools $25 \%$ of the Dutch indicated that they had very few contacts with ethnic minorities. This suggests that also in the Netherlands there seems to be a tendency toward what Ward Schofield (1986) calls resegregation within schools. Common educational practices such as streaming, as well as voluntary behavior of pupils in a variety of situations, often lead to partial resegregation within multiethnic schools. Trying to change this pattern seems an important condition for improving ethnic group relations. The fact that school can play a major role in stimulating cross-ethnic contact also is suggested by the finding that outside the school the amount of contact was significantly less. The difference in amount of contact between inside and outside school indicates the importance of the institution school for cross-ethnic contact, even in multiethnic neighborhoods. However, as long as cross-ethnic contact mainly is restricted to the context of school, where contact can be more compulsory, it is unclear if it has a generalized effect on the level of ingroup formation and preference among Dutch adolescents.

In the present study prejudice did not explain a significant part of the variance in ingroup formation and preference (cf. Kawwa, 1968), apart from the effect for ethnic identity and rate of contact, although the prejudice measure was the most extensive and reliable one. An interpretation for this finding could be that prejudice is measured at a more general level than ethnic preferences. The prejudice scale refers to foreigners and different peoples whereas the group preferences refer to specific ethnic groups. However, the prejudice scale showed a strong correlation with evaluative state- 
ments concerning a specific minority group (the Turks). Another interpretation could be that there were few indications of clear prejudicial attitudes toward ethnic minorities. It could be argued that especially youngsters holding strong negative views toward ethnic minorities reject contemporaries from minority groups. Prejudice could have a threshold effect for ethnic group relations.

In the present study the majority of the subjects were not strongly prejudiced and the results indicated that for these subjects prejudicial attitudes were dependent especially on the evaluation of ethnic identity. An explanation might be that prejudice may represent an attempt to enhance ethnic identity (see Crocker \& Luhtanen, 1990). If prejudice is indeed a function of positive identification with the Dutch as a group, then two things follow (see also Reicher, 1986). First, the nature of one's prejudicial attitudes will depend on group norms, so that it is not (negative) contact with ethnic minorities but contact with a prejudiced tradition that leads to prejudice. Second, if prejudice is related to identity, then it is dependent on using ethnic origin to identify both oneself and others. The practical implication is that one has to be careful in using ethnic categories. Especially in the field of education, programs for the reduction of prejudice stress ethnic origin. An unintended effect of these programs might be that ethnic identifications become more salient and important with the result that own-group orientations and prejudice may be more outspoken. Ethnic origin, however, is not the only categorical distinction that can be used. It can be overshadowed by other identities such as school membership, sex, and neighborhood, which should result in a reduction in ethnic prejudice. There is some experimental evidence that bringing alternative categorizations into play can reduce the conflict surrounding the original division (see Deschamps \& Doise, 1978: Vanbeselaere, 1991). Other identities can be stressed in order to prevent ethnic origin becoming a persuasive category with prejudice attached to it. On the other hand, it must not be forgotten that ethnic origin has its own psychological functions, certainly also for minorities, and that ethnic minorities themselves can stress their origin and value their ethnic identity.

A final remark concerns the level of prejudice among the Dutch youth. Earlier we concluded that the majority of the subjects did not show a strong prejudicial attitude toward ethnic minorities. On the other hand, especially outside school, almost half of the subjects indicated that they almost never had contact with ethnic minorities. This suggests that the more neutral attitude toward ethnic minorities must be interpreted carefully. There are two other reasons for caution. First, under conditions perceived to embody a relatively stable intergroup status hierarchy, the dominant group will probably not be overtly prejudiced or discriminatory (see Hogg, Abrams, \& Patel, 1987). Second, the "modern" or "symbolic" racism approach (McConahay \& 
Hough, 1976) suggests that it is unlikely that the prejudiced person holds, or at least expresses, attitudes that outrightly demean ethnic minorities. The existing social norm against being or appearing prejudiced is generally recognized and consequently not admitted of the self but much more located outside the self.

To conclude, the present study suggests that improving ethnic group relations implies more than combatting prejudicial attitudes. Not so much the rejection or dislike of ethnic minority groups seems important but especially the orientation toward the own group and the amount of cross-ethnic contact. Many studies concentrate on prejudice and in doing so probably overestimate its importance. A broader view including different perspectives seems necessary to extend our understanding of ethnic group relations.

\section{References}

Aboud, F. (1988). Children and prejudice. Oxford: Blackwell.

Allport, G.W. (1954). The Nature of prejudice. Reading, MA: AddisonWesley.

Amir, Y. (1969). Contact hypothesis in ethnic relations. Psychological Bulletin, 71, 319-342.

Bagley, C., Verma, G. K., Mallick, K., \& Young, L. (1979). Personality, self-esteem and prejudice. Westmead, Farnborough: Saxon House.

Brewer, M. B., \& Miller, N. (1984). Beyond the contact hypothesis: theoretical perspectives on desegregation. In N. Miller \& M. B. Brewer (Eds.), Groups in contact: The psychology of desegregation. New York: Academic Press.

Brown, R. J., \& Turner, J. A. (1981). Interpersonal and intergroup behaviour. In J. C. Turner \& H. Giles (Eds.), Intergroup Behaviour (pp. 3365). Oxford: Blackwell.

Crocker, J., \& Luhtanen, R. (1990). Collective self-esteem and ingroup bias. Journal of Personality and Social Psychology, 58, 60-67.

DeJong, M., \& Van Der Toorn, H. (1984). Etnisch vooroordeel onder middelbare scholieren [Ethnic prejudice among secondary school pupils]. Pedagogisch Tijdschrift, 9, 509-517.

Deschamps, J. C., \& Doise, W. (1978). Crossed category memberships in intergroup relations. In $\mathrm{H}$. Tajfel (Ed.), Differentiation between groups (pp. 142-158). London: Academic Press.

Hewstone, M. R. C., \& Brown, R. J. (1986). Contact is not enough: an intergroup perspective on the contact hypothesis. In M. R. C. Hewstone \& R. J. Brown (Eds.), Contact and conflict in intergroup encounters (pp. 1-44). Oxford: Blackwell.

Hinkle, S., \& Schopler, J. (1986). Bias in the evaluation of in-group and 
out-group performance. In S. Worchel \& W. Austin (Eds.), Psychology of intergroup relations (pp. 196-212). Chicago: Nelson-Hall.

Hogg, M. (1987). Social identity and group cohesiveness. In J. C. Turner, M. A. Hogg, P. J. Oakes, S. D. Reicher, \& M. S. Wetherell (Eds.), Rediscovering the social group: A self-categorization theory (pp. 89-116). Oxford: Blackwell.

Hogg, M., \& Abrams, D. (1988). Social identifications: A social psychology of intergroup relations and group processes. London: Routledge.

Hogg, M., Abrams, D., \& Patel, Y. (1987). Ethnic identity, self-esteem, and occupational aspirations of Indian and Anglo-Saxon British adolescents. Genetic, Social, and General Psychology Monograph, 113, 487-508.

Hogg, M. A., \& Turner, J. C. (1985). When liking begets solidarity: an experiment on the role of interpersonal attraction in psychological group formation. British Journal of Social Psychology, 24, 267-281.

Hutnik, N. (1986). Patterns of ethnic minority identification and modes of social adaptation. Ethnic and Racial Studies, 9, 150-167.

Kawwa, T. (1968). A survey of ethnic attitudes of some British secondary school pupils. British Journal of Social and Clinical Psychology, 7, 161-168.

McConahay, J. B., \& Hough, J. C. (1976). Symbolic racism. Journal of Social Issues, 32, 23-45.

McGuire, W. J., McGuire, C. V., Child, P., \& Fujioka, T. (1978). Salience of ethnicity in the spontaneous selfconcept as a function of one's ethnic distinctiveness in the social environment. Journal of Personality and Social Psychology, 36, 511-520.

Milner, D. (1984). The development of ethnic attitudes. In H. Tajfel (Ed.), The social dimension (Vol. 1, pp. 89-110). Cambridge: Cambridge Univ. Press.

Nederhof, A. J. (1981). Beter onderzoek: bestrijding van fouten bronnen in sociaal-wetenschappelijk onderzoek [Doing better research: Challenging biases in social scientific research]. 's-Gravenhage, the Netherlands: Vuga.

Phinney, J.S. (1990). Ethnic identity in adolescents and adults: review of research, Psychological Bulletin, 108, 499-514.

Reicher, S. (1986). Contact, action and racialization: some British evidence. In M. R. C. Hewstone \& R. J. Brown (Eds.), Contact and conflict in intergroup encounters (pp. 152-168). Oxford: Blackwell.

Rotheram-Borus, M. J. (1990), Adolescents' reference-group choices, selfesteem, and adjustment. Journal of Personality and Social Psychology, 59, 1075-1081.

Sachdev, I., \& Bourhis, R. Y. (1987). Status differentials and intergroup behavior. European Journal of Social Psychology, 17, 277-293.

Tajfel, H., \& Turner, J. C. (1979). An integrative theory of intergroup con- 
flict. In W. G. Austin \& S. Worchel (Eds.), The social psychology of intergroup relations (pp. 7-24). Monterey, CA: Brooks-Cole.

Turner, J. C. (1982). Towards a cognitive redefinition of the social group. In H. Tajfel (Ed.), Social identity and intergroup relations (pp. 15-39). Cambridge: Cambridge Univ. Press.

Ullah, P. (1987). Self-definition and psychological group formation in an ethnic minority. British Journal of Social Psychology, 26, 17-23.

Vanbeselaere, N. (1991). The different effects of simple and crossed categorizations: a result of the category differentiation process or of differential category salience? In: W. Stroebe \& M. Hewstone (Eds.), European review of social psychology (Vol. 2, pp. 247-278). London: Wiley.

Verkuyten, M. (1990). Self-esteem and the evaluation of ethnic identity among Turkish and Dutch adolescents in the Netherlands. Journal of Social Psychology, 130, 285-297.

Verkuyten, M. (1991). Self-definition and ingroup formation among ethnic minorities in the Netherlands. Social Psychology Quarterly, 54, 280-286.

Verkuyten, M. (1992). Zelfbeleving van jeugdige allochtonen: een sociopsychologische benadering [Self-concept among ethnic minority youth: a socio-psychological approach]. Lisse, Netherlands: Swets \& Zeitlinger.

Verkuyten, M. (in press). Ethnic group preferences and the evaluation of ethnic identity among adolescents in the Netherlands. Journal of Social Psychology.

Wagner, U., \& Machleit, U. (1986). "Gastarbeiter" in the Federal Republic of Germany: Contact between Germans and migrant populations. In M. Hewstone \& R. Brown (Eds.), Contact and conflict in intergroup encounters (pp. 59-77). Oxford: Basil Blackwell.

Ward Schofield, J. (1986). Black-White contact in desegregated schools. In M. Hewstone \& R. Brown (Eds.), Contact and conflict in intergroup encounters (pp. 79-92). Oxford: Basil Blackwell. 